the record. It would be interesting to have this accurately stated, and more widely published.

At Bangalore, in the Mysore Province, I once registere an inch and a quarter in twenty minutes ; and seven and eight, and more inches have been occasionally gauged during a heavy twenty-four hours' fall, notably so in 1856 , when disastrous floods occurred. Somewhere about that period a most extraordinary fall of rain occurred at Madras. I regret that I have not the record by me, but $I$ am right in saying that more than twenty. three inches fell in twenty-four hours! and that more than seven inches fell within six hours! This was gauged at the Madras Observatory, and registered every hour ; the statement can therefore be easily corroborated by a reference to the superintendent at that place. A coffee planter on the western Ghauts of Mysore

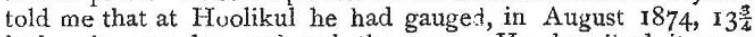
inches in one day, and $10 \frac{1}{4}$ the next. He described it as a sullen, intermittent, continuous downpour, the monotony of which was very depressing. At Mahableshwar, on the same line of Ghauts, the average fall is 240 inches, chiefly in the four or five months, from May to September inclusive ; while at the Cherrapoonji Hills, not very far from Calcutta, the average fall is over 600 inches, or (say) seventeen yards of rain! My notes are in a book that I left in India, but I am within the mark in what has been stated above.

The meteorology of India would furnish many startling incidents. It has not hitherto been sufficiently attended to, or recorded, and much valuable time has been allowed (like the rainfall) to run by; but attention is now, I believe, being paid to its systematic registry, and to the publication of accurate results. I have some interesting records, however, of the Province of Myscre, which I would gladly place at your disposal should you desire to have them.

J. PUCKLE

\section{A New Palmistry}

IT is the old story-" In striving to be concise, I have become obscure." If Mr. Mott will refer to my abstract of Prof. Ecker's paper, he will find directions as to procedure, very briefly stated, I will grant; for I, and others too, more competent to judge than myself, had no idea that the subject would attract the attention which it has done. At Mr. Mott's desire, however, I give lim a literal translation of Prof. Ecker's directions (op. cit. P. 73) in full :-

"With regard to the method of measurement on living individuals, I will merely remark that the hand must be simply laid, with the fingers closed together, upon a board or a piece of paper, upon which a well-defined perpendicular line has been drawn. With this latter the axis of the middle finger and its metacarpal bone is made precisely to coincide. Every lateral movement of the middle finger naturally alters also the position of the other fingers, and every movement of the fingers upon the metacarpal bones towards the pollex turns to the advantage of the position of the index, while that toward the little-finger-edge of the hand to the advantage of that of the ring-finger. The tips of the fingers (without nails $d$ la Chtnois) are then outlined with a pencil, halved longitudinally ; its cut surface being applied against them."

John C. Galton

$$
\text { Nov. } 29
$$

I IFAVE made a number "of determinations of the relative lengths of the "index" and "ring" fingers of both hands, the results of which, I think, very decidedly show that there is a great dissimilarity between the two hands. The hands of twentytwo persons were examined; in ten there was similarity between the hands as regards the relative lengths of the two fingers in question; in twelve there was dissimilarity. In the case of eight question; in " was longer than the "index ;" in one case the "index" was the longer, and in the remaining instance the two fingers were of equal length. Of the twelve cases which exhibited dissimilarity, six had the "ring" longer than the "index" in the left hand, and five in the right hand; four had the "index" longer than the "ring" in the left hand, and in three the same reiation existed in the right hand.

M. M. Pattison Muir

The Owens College, Manchester, Nov. 27

\section{Faye on the Laws of Storms}

M. FAYE's paper on cyclones and waterspouts, of which you have lately published a full abstract, seems very unsatisfactory. The statement in NATURE, vol. xii. p. 4OI, of the laws of the cy- clone's motion is no doubt true, but it is avowedly not original. But the succeeding parts, where the dynamics of the subject are treated of, cannot be sufficient-I think I may say cannot be sound-because they take no account of the very remarkable facts of the geographical distribation of cyclones. If M. Faye's theory were true and complete, cyclones ought to be equally common in all equatorial and tropical regions, except perhsps that they ought to be commonest in the hottest parts. So far is this from being the case, that they are strictly local phenomena. They are formed in the West Indian seas, but not in the South Atlantic; in the Indian Ocean, both north and south of the equator, hut much oftener on the eastern than on the western side of India; and, I believe, off the coast of Calif urnia, but not that of Peru. Their periodicity is equally remarkahle. In the West Indian and in the Chinese seas they occur chiefly at the end of summer, but in the Bay of Bengal atter the equinoxes.

All these facts point to the origin of the cyclone, not, as M. Faye seems to think, in eddies formed in the upper currents of the atmosphere-how could eddies be formed in currents so totally free from obstructions?-but in eddies formed by the meeting and conflict of the two trade-winds where one of them is drawn across the equator. This hypothesis agrees with observation, and harmonises all the geographical facts relating to cyclones.

This simple and true theory is stated in a paper on the Law of Storms by Prof. Maury, in NATURE of June 12, I9, and 26 , 1873. It had previously been stated for the Bay of Bengal, as the result of an examination of particular storms, by $\mathrm{Mr}$. Meldrum, in a paper read before the Meteorological Society of Mauritius, and reported in NATURE, vol. ii. p. I5I ; and a letter of mine in NATURE, vol. iv. p. 305 , maintained the probability of all cyclones so originating.

I think M. Faye is as unsatisfactory on waterspouts as on cyclones, I hope to follow this by a letter on waterspouts.

Oid Forge, Dunmurry, Co. Antrim, Nov, I JOSEPH JOHN MURPHY

\section{OUR ASTRONOMICAL COLUMN}

SATELLITES OF URANUS,-There are many amateurs in this country who possess instruments quite competent to show the two larger or exterior satellites of the planet Uranus, With the view to facilitate the identification of these objects, their angles of position and distances from the centre of Uranus are given below for I4 $\mathrm{a}$. Greenwich mean time for the last ten days of the present year, with the intention of continuing them while the planet is most favourably placed for observation as regards position and distance from the moon's place. They are deduced from the very converient tables appended by Prof. Newcomb to his discussion of the observations of the satellites with the 26 inch equatorial at Washington, forming Appendix I. to the Washington Observations for I873:-

\begin{tabular}{|c|c|c|c|c|c|c|c|c|c|}
\hline G M. & & & TTANIA. & & & & & ERON. & \\
\hline $19 \ldots$ & Pos. & $48 \cdot 0$ & Dist. & 20.8 & $\ldots$ & Pos. & $64 \cdot 2$ & Dist. & 23 \\
\hline $20 \ldots$ & , & $18: 3$ & " & $32 \cdot 3$ & $\cdots$ & $"$ & 33.8 & , & \\
\hline $21 \ldots$ & ", & $359^{\circ} 6$ & ," & $32 \cdot 1$ & $\ldots$ & " & 18.1 & $"$ & \\
\hline $22 \ldots$ & " & 3292 & ," & 20.5 & $\ldots$ & ", & $6 \cdot 1$ & $"$ & \\
\hline $23 \ldots$ & ," & $249^{\circ} 6$ & , & 16.6 & $\cdots$ & ," & $35^{2} 9$ & , & \\
\hline $24 \ldots$ & $"$ & $206 \cdot I$ & ", & $29 \cdot 3$ & $\ldots$ & ", & 3314 & $"$ & \\
\hline $25 \ldots$ & $"$ & 186.4 & ", & 33.9 & $\cdots$ & " & $285^{\circ} 2$ & ", & \\
\hline $26 \quad$. & , & 163.4 & ," & 254 & $\ldots$ & ," & 2334 & $"$ & \\
\hline $27 \ldots$ & , & 100.8 & $"$ & 149 & $\ldots$ & ", & 208.8 &, & \\
\hline $28 \ldots$ & ", & $3^{6 \cdot 2}$ & " & $25^{\circ} \mathrm{O}$ & $\ldots$ & $"$ & 1947 & ", & \\
\hline $29 \quad$. & ", & 129 & ", & 339 & $\cdots$ & ", & 182.9 & $"$ & \\
\hline $30 \ldots$ & ", & $353^{\prime 2}$ & ", & 29.7 & $\cdots$ & ", & 168.4 & " & \\
\hline $3 \mathbf{I} \ldots$ & ", & & ", & $17^{\circ} \mathrm{O}$ & $\cdots$ & , & 14222 & , & \\
\hline
\end{tabular}

The above angles are reckoned as is usual in measures of double stars, i.e., from the $\mathrm{N}$. point round by the east. The apparent diameter of Uranus by the Malta determination of Lassell and Marth will be $3^{\prime \prime} \cdot 87$ on December 25 th. With this value, should it be found more convenient, the arc values may be reduced to distances in diameters of the planet.

The Minor Planets.-No. 156 is announced as having been discovered by Herr Palisa, at Pola, on Nov. 22, in R.A. 2 h. $54 \mathrm{~m}$, , and N.P.D. $70^{\circ} 23^{\prime}$ : it is of 